\title{
Perspective \\ Computational Simulator Models and Invasive Hemodynamic Monitoring as Tools for Precision Medicine in Pulmonary Arterial Hypertension
}

\author{
Giovanna Manzi ${ }^{1}$, Cristiano Miotti ${ }^{1} \mathbb{D}$, Marco Valerio Mariani $^{1} \mathbb{D}$, Silvia Papa ${ }^{1} \mathbb{D}$, Federico Luongo ${ }^{1}(\mathbb{D}$, \\ Gianmarco Scoccia $^{1} \mathbb{D}$, Beatrice De Lazzari ${ }^{2}$, Claudio De Lazzari $^{3} \mathbb{D}$, Raymond L. Benza ${ }^{4}$, Francesco Fedele ${ }^{1}$, \\ Carmine Dario Vizza ${ }^{1}$ and Roberto Badagliacca ${ }^{1, *}$
}

1 Department of Clinical, Anesthesiological and Cardiovascular Sciences, Sapienza University of Rome, Viale del Policlinico, 155, 00161 Rome, Italy; giovannamanzi91@gmail.com (G.M.); miotticristiano@gmail.com (C.M.); marcoval.mariani@gmail.com (M.V.M.); silviapapa83@gmail.com (S.P.); federico.luongo91@gmail.com (F.L.); gianmarcoscoccia@gmail.com (G.S.); francesco.fedele@uniroma1.it (F.F.); dario.vizza@uniroma1.it (C.D.V.)

2 Department of Engineering, Roma Tre University, 00146 Rome, Italy; beatrice.delazzari@gmail.com

3 National Research Council, Institute of Clinical Physiology (IFC-CNR), 00185 Rome, Italy; claudio.delazzari@ifc.cnr.it

4 Division of Cardiovascular Diseases, Ohio State University, Columbus, OH 43210, USA; Raymond.Benza@ahn.org

* Correspondence: roberto.badagliacca@uniroma1.it

check for updates

Citation: Manzi, G.; Miotti, C.; Mariani, M.V.; Papa, S.; Luongo, F.; Scoccia, G.; De Lazzari, B.; De Lazzari, C.; Benza, R.L.; Fedele, F.; et al. Computational Simulator Models and Invasive Hemodynamic Monitoring as Tools for Precision Medicine in Pulmonary Arterial Hypertension. J. Clin. Med. 2022, 11 82. https://doi.org/10.3390/ jcm11010082

Academic Editors: Gabor G. Kovacs and Dinesh K. Kalra

Received: 21 November 2021 Accepted: 21 December 2021 Published: 24 December 2021

Publisher's Note: MDPI stays neutral with regard to jurisdictional claims in published maps and institutional affiliations.

Copyright: (C) 2021 by the authors. Licensee MDPI, Basel, Switzerland. This article is an open access article distributed under the terms and conditions of the Creative Commons Attribution (CC BY) license (https:// creativecommons.org/licenses/by/ $4.0 /)$.

\begin{abstract}
Precision medicine, providing the right therapeutic strategy for the right patient, could revolutionize management and prognosis of patients affected by cardiovascular diseases. Big data and artificial intelligence are pivotal for the realization of this ambitious design. In the setting of pulmonary arterial hypertension (PAH), the use of computational models and data derived from ambulatory implantable hemodynamic monitors could provide useful information for tailored treatment, as requested by precision medicine.
\end{abstract}

Keywords: implantable hemodynamic monitors; computational models; pulmonary arterial hypertension; precision medicine; big data

\section{Introduction}

Advances in panomics, including genomics, proteomics, transcriptomics and metabolomics, are paving the way for the shift from population-based clinical decision making to a true personalization of care based on individual genetic and environmental factors. Despite the success achieved with medical reductionism, the idea that all patients with the same disease should be treated similarly is too limited to be accepted today [1]. Treating the patient, not the disease is the goal for precision medicine.

In spite of advances achieved with drugs targeting the endothelin, nitric oxide and prostacyclin pathways involved in the disease, $\mathrm{PAH}$ is still characterized by high morbidity and mortality rates $[2,3]$. Thus, the current challenge is the development of personalized medicine strategies, providing the right treatment to the right patient [4].

Omic technologies, big data and artificial intelligence could contribute to realizing this ambitious goal, allowing a step forward in current clinical practice (Figure 1).

As the right ventricle (RV) is the main determinant of patient's prognosis [5], computational models simulating the effects of increased afterload on RV function and predicting response to specific drugs could aid physicians in optimizing PAH understanding, prognosis and clinical decision making. Versatility, reliability, simplicity and low execution time are pivotal for the success of these models.

The present paper focuses on new potential opportunities offered by computational models and data derived from ambulatory implantable hemodynamic monitoring (IHM), used to provide useful information for PAH patient management, as expected in the precision medicine era. 


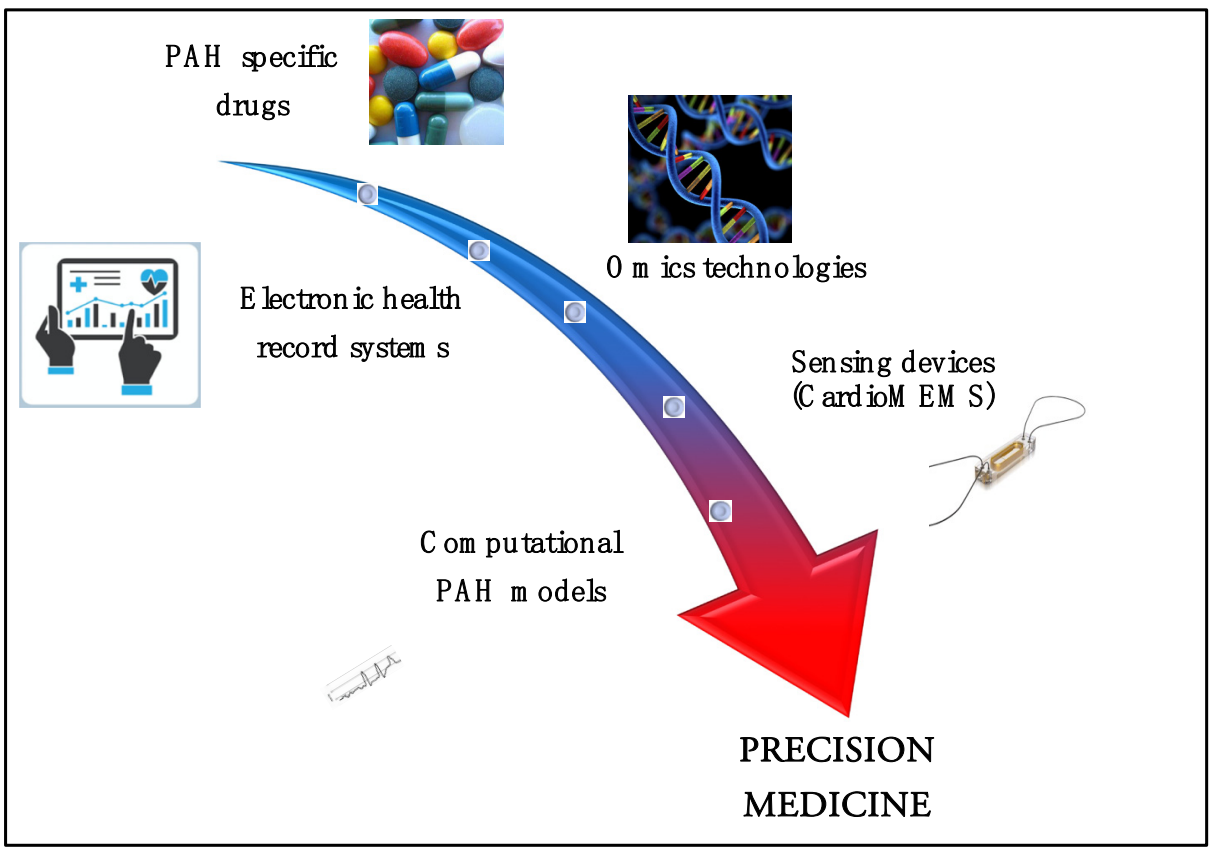

Figure 1. Hypothetical pathway for precision medicine in PAH. Treating the patient, not the disease, is the goal for precision medicine. Panomics, phenotyping, big data derived from electronical health systems and sensing devices, and artificial intelligence with the use of computational simulators could contribute to developing this ambitious goal in $\mathrm{PAH}$, overcoming the current limitations of reductionism.

\section{A Look at Omic Technologies in PAH}

The current World Symposium on Pulmonary Hypertension (WSPH) classification categorizes patients on the basis of similar clinical and hemodynamic patterns without considering differences in genomics, proteomics, transcriptomics and metabolomics. Indeed, only two of the five categories, $\mathrm{PAH}$ and pulmonary veno-occlusive disease/pulmonary capillary haemangiomatosis, are linked to molecular mechanism. Similarly, current PAH treatment strategies primarily target pulmonary vasoconstriction, without taking into account recent advances in omics fields. Omic technologies could overcome these limitations and enhance clinical research in $\mathrm{PAH}$, generating new understanding of the disease and improving both diagnosis and treatment.

The description of all omics technologies goes beyond the aim of this perspective paper; however, we choose briefly mention genomics.

The most common genetic cause of PAH involves the gene encoding the bone morphogenetic protein receptor type II (BMPR2), a receptor for the transforming growth factor (TGF)- $\$$ protein superfamily, particularly expressed on the pulmonary vascular endothelium. The reduction in expression or function of BMPR2 signaling leads to altered cellular responses to TGF-B.

Since the identification of BMPR2 mutations, the PAH genetic landscape has significantly expanded, with novel causative genes detected by new-generation sequencing methodologies (e.g., SMAD9, CAV1, EIF2AK4, ENG) [6]. Genomics advances could lead to progress in PAH therapy through the development of new drugs targeted to mutational correction.

To achieve a comprehensive phenotyping of $\mathrm{PH}$ patients allowing a more efficacious approach of the PH classification in terms of clinical impact, the National Institutes of Health (NIH)/National Heart, Lung and Blood institute (NHLBI) recently launched an ongoing initiative called "Redefining pulmonary Hypertension through Pulmonary Vascular Diseas Phenomics (PVDOMICS)" [7,8]. To date, the study has enrolled approximately 1200 adult participants with $\mathrm{PH}$, classified according to the traditional WSPH groups one to five, or with risk factors for $\mathrm{PH}$ or healthy control individuals. All participants underwent a deep clinical, imaging and hemodynamic assessment and blood analysis through sam- 
ples obtained from the peripheral vein, pulmonary artery and distal-to-pulmonary artery occlusion for a broad collection of selected omics tests. The large dataset deriving from PVDOMICS, including clinical and omic biobanks, will represent a precious and unique resource available for future $\mathrm{PH}$ investigations.

\section{Ambulatory Implantable Hemodynamic Monitors: A New Source of Big Data}

Big data, referring to the storage and analysis of large volumes of medical information from individual patient data, provide a unique opportunity to improve health, identify personalized therapeutic options and detect different treatment responses to therapy [9]. The main sources of big data include: (a) the electronic patient-health-record systems (EHR), allowing physicians to store, process and share electronically patients' medical data for the coordination of multicenter registries and (b) sensing devices, wearable and implantable devices for the continuous monitoring of specific parameters [10]. The huge amount of data derived from EHR and sensing devices has radically changed the management of PAH over the last two decades, as well as other cardiovascular diseases.

\section{Novel Devices for Monitoring Pulmonary Arterial Hypertension Patients}

PAH is an obstructive pulmonary vasculopathy characterized by a progressive increase in pulmonary vascular resistance (PVR) that leads to RV overload, and ultimately, RV failure. The close monitoring of pulmonary arterial pressure and RV function could help clinicians tailor the best therapeutic strategy in order to improve patients' outcome and reduce hospitalization rates [11,12]. Indeed, PAH patients' functional status and prognosis mostly depend on the ability of the RV to adapt to the increased afterload [13]. In the earlier stages, the increased RV contractility, with little or no increase in right heart chamber dimensions, allows for preserving cardiac output. In the later stages of the disease, the homeometric adaptation fails and the stroke volume is maintained by progressive increase in RV end-diastolic volume (heterometric adaptation) [14,15]. The consequent tricuspid functional regurgitation leads to additional RV volume overload. Finally, the leftward displacement of the interventricular septum and the left ventricle (LV) underfilling due to reduced RV cardiac output accounts for the heart failure (HF) syndrome [16].

In this scenario, optimal management of PAH patients strongly relies on the assessment of RV function, RV remodeling and hemodynamic status [17-19]. Echocardiography is the first-line technique for the evaluation of RV size and function [20,21], but does not provide robust hemodynamic data. Conversely, right heart catherization allows for a comprehensive hemodynamic assessment, but it is an invasive procedure with technical challenges, and it must be performed in a clinic, providing a snapshot of patient's hemodynamics at a single time point. Ambulatory IHMs, such as CardioMEMS ${ }^{\mathrm{TM}}$ (Abbott, Sylmar, CA, USA), providing frequent remote hemodynamic measurements in the home setting and recording the variability of pulmonary pressure during the day, provide additional information for PAH patients' management, potentially overcoming the above limitations [22].

\section{The CardioMEMS System}

IHMs have recently been approved for the management of patients with HF [23], aiding physicians to adjust HF therapy before the development of congestive symptoms [24]. As recommended by the 2016 ESC Heart Failure Guidelines [25], the wireless CardioMEMS $^{\mathrm{TM}}$ system may be considered (class IIb) for the monitoring of pulmonary artery pressure in symptomatic patients with HF with previous HF hospitalization, in order to reduce the risk of recurrent HF hospitalization.

Conversely, the experience of IHMs in the management of patients with PAH is still limited to small series. CardioMEMS system implantation in $26 \mathrm{PAH}$ patients with NYHA class III or IV has recently shown that IHMs may represent a promising tool to early identify decompensation or noncompliance, to reassess response to therapy and to allow rapid drug titration, reducing in-person visits and invasive hemodynamic assessments [22,26]. Importantly, while clinical experience with IHMs in PAH is increasing, providing a huge amount 
of data, IHMs represent a unique opportunity to improve and validate computational cardiovascular simulators in this setting. However, randomized, larger clinical trials are needed before these devices can be routinely used in clinical practice.

\section{Computational Cardiovascular Simulators}

Advances in technology have led to the development of computational simulators, which are useful in research, clinical and e-learning environmental settings [27].

In the field of cardiovascular diseases, the most used numerical simulators provide a representation of the left and right heart, systemic, pulmonary and coronary circulation, relying on pressure-volume relationships and lumped-parameter models [28-30].

Computational simulators are intended as interactive software for reproducing physiological and pathological clinical conditions. Usually these are characterized by a modular approach, consisting of a basic core module and supplementary, highly specialized modules. As an example, we may consider the following supplementary modules:

- $\quad$ Supplementary modules for ventricular assist devices;

- A supplementary module to reproduce the biventricular pacemaker behavior;

- A supplementary module for the total artificial heart;

- A supplementary module for intra-aortic balloon pumping;

- A supplementary module for the thoracic artificial lung.

Combining these modules, clinicians may virtually reproduce patient's hemodynamic conditions, simulate the effects of different therapeutic interventions in real time and obtain accurate prediction of device performance. Thus, such computational simulators (e.g., CARDIOSIM, CircAdapt Simulator, HemoLab and Harvi) could support physicians in clinical decision making [31-34].

Computational simulators might also play a pivotal role in unravelling the cardiopulmonary unit response to different therapeutic strategies in the complex PAH pathophysiology. Indeed, computational simulators accurately describing the interaction between the respiratory and the circulatory system might correctly reproduce the hemodynamic and respiratory condition of PAH patients, allowing the right drug for the right patient. Nevertheless, only few systems currently include hemodynamic and ventilatory variables coupling the cardiovascular and respiratory system, allowing a complete simulation of PAH pathophysiology. The optimization and the widespread diffusion of computational PAH simulators in daily clinical practice require strict cooperation between model developers and PAH specialists.

\section{Conclusions}

The exponential growth in technology may add a significant contribution to patients' management and potentially improve the prognosis of patients affected by cardiovascular diseases such as PAH. Reproducing pathophysiological conditions and simulating the effects of drugs and interventional procedures on the cardiovascular system, computational simulators may become a new approach in clinical practice. The validation of these systems, useful for their strength and clinical applications, remains a major issue. Big data derived from electronic patient-health-record systems and ambulatory IHMs could be used to improve and validate computational PAH simulators, welcoming precision medicine era into the PAH field.

Author Contributions: Conceptualization: R.B., G.M., R.L.B. and C.D.V.; methodology: G.M., R.B., C.D.L. and F.F.; resources: G.M., R.B. and M.V.M.; writing-original draft preparation: G.M., R.B., M.V.M., C.M. and G.S.; writing-review and editing: G.M., R.B., M.V.M., S.P., F.L. and B.D.L.; supervision: R.B., R.L.B., F.F. and C.D.V. All authors contributed to the work. All authors have read and agreed to the published version of the manuscript.

Funding: This research received no external funding.

Institutional Review Board Statement: Not applicable. 
Informed Consent Statement: Not applicable.

Data Availability Statement: Not applicable.

Conflicts of Interest: C.D. Vizza reports personal fees from GSK, UT, Dompè, Bayer, MSD, outside the submitted work. R. Badagliacca reports personal fees from UT, Dompè, Ferrer, Bayer, MSD, AOP Orphan Pharmaceuticals, outside the submitted work. R.L. Benza reports receiving grants from Actelion, Bayer AG, Bellerophon, Eiger and Abbott. The other authors reported no conflicts of interest.

\section{References}

1. Ahn, A.C.; Tewari, M.; Poon, C.S.; Phillips, R.S. The limits of reductionism in medicine: Could systems biology offer an alternative? PLoS Med. 2006, 3, e208. [CrossRef] [PubMed]

2. Sitbon, O.; Galiè, N. Treat-to-target strategies in pulmonary arterial hypertension: The importance of using multiple goals. Eur. Respir. Rev. 2010, 19, 272-278. [CrossRef] [PubMed]

3. Benza, R.L.; Park, M.H.; Keogh, A.; Girgis, R.E. Management of pulmonary arterial hypertension with a focus on combination therapies. J. Heart Lung Transpl. 2007, 26, 437-446. [CrossRef] [PubMed]

4. Savale, L.; Guignabert, C.; Weatherald, J.; Humbert, M. Precision medicine and personalising therapy in pulmonary hypertension: Seeing the light from the dawn of a new era. Eur. Respir. Rev. 2018, 27, 180004. [CrossRef] [PubMed]

5. Badagliacca, R.; Papa, S.; Matsubara, H.; Lang, I.M.; Poscia, R.; Manzi, G.; Vizza, C.D. The importance of right ventricular evaluation in risk assessment and therapeutic strategies: Raising the bar in pulmonary arterial hypertension. Int. J. Cardiol. 2020, 301, 183-189. [CrossRef]

6. Morrell, N.W.; Aldred, M.A.; Chung, W.K.; Elliott, C.G.; Nichols, W.C.; Soubrier, F.; Trembath, R.C.; Loyd, J.E. Genetics and genomics of pulmonary arterial hypertension. Eur. Respir. J. 2019, 53, 1801899. [CrossRef]

7. Oldham, W.M.; Hemnes, A.R.; Aldred, M.A.; Barnard, J.; Brittain, E.L.; Chan, S.Y.; Cheng, F.; Cho, M.H.; Desai, A.A.; Garcia, J.G.N.; et al. NHLBI-CMREF Workshop Report on Pulmonary Vascular Disease Classification: JACC State-of-the-Art Review. J. Am. Coll. Cardiol. 2021, 77, 2040-2052. [CrossRef]

8. Hemnes, A.R.; Beck, G.J.; Newman, J.H.; Abidov, A.; Aldred, M.A.; Barnard, J.; Berman Rosenzweig, E.; Borlaug, B.A.; Chung, W.K.; Comhair, S.A.; et al. PVDOMICS: A Multi-Center Study to Improve Understanding of Pulmonary Vascular Disease Through Phenomics. Circ. Res. 2017, 121, 1136-1139. [CrossRef]

9. Hulsen, T.; Jamuar, S.S.; Moody, A.R.; Karnes, J.H.; Varga, O.; Hedensted, S.; Spreafico, R.; Hafler, D.A.; McKinney, E.F. From Big Data to Precision Medicine. Front. Med. 2019, 6, 34. [CrossRef]

10. Leff, D.R.; Yang, G. Big data for precision medicine. Engineering 2015, 1, 277-279. [CrossRef]

11. Badagliacca, R.; D’Alto, M.; Ghio, S.; Argiento, P.; Bellomo, V.; Brunetti, N.D.; Casu, G.; Confalonieri, M.; Corda, M.; Correale, M.; et al. Risk Reduction and Hemodynamics with Initial Combination Therapy in Pulmonary Arterial Hypertension. Am. J. Respir. Crit. Care Med. 2021, 203, 484-492. [CrossRef] [PubMed]

12. D'Alto, M.; Badagliacca, R.; Lo Giudice, F.; Argiento, P.; Casu, G.; Corda, M.; Correale, M.; Ghio, S.; Greco, A.; Lattanzio, M.; et al. Hemodynamics and risk assessment 2 years after the initiation of upfront ambrisentan-tadalafil in pulmonary arterial hypertension. J. Heart Lung Transpl. 2020, 39, 1389-1397. [CrossRef] [PubMed]

13. Badagliacca, R.; Raina, A.; Ghio, S.; D’Alto, M.; Confalonieri, M.; Correale, M.; Corda, M.; Paciocco, G.; Lombardi, C.; Mulè, M.; et al. Influence of various therapeutic strategies on right ventricular morphology, function and hemodynamics in pulmonary arterial hypertension. J. Heart Lung Transpl. 2018, 37, 365-375. [CrossRef] [PubMed]

14. Vonk Noordegraaf, A.; Chin, K.M.; Haddad, F.; Hassoun, P.M.; Hemnes, A.R.; Hopkins, S.R.; Kawut, S.M.; Langleben, D.; Lumens, J.; Naeije, R. Pathophysiology of the right ventricle and of the pulmonary circulation in pulmonary hypertension: An update. Eur. Respir. J. 2019, 53, 1801900. [CrossRef]

15. Badagliacca, R.; Poscia, R.; Pezzuto, B.; Papa, S.; Pesce, F.; Manzi, G.; Giannetta, E.; Raineri, C.; Schina, M.; Sciomer, S.; et al. Right ventricular concentric hypertrophy and clinical worsening in idiopathic pulmonary arterial hypertension. J. Heart Lung Transpl. 2016, 35, 1321-1329. [CrossRef] [PubMed]

16. Badagliacca, R.; Poscia, R.; Pezzuto, B.; Nocioni, M.; Mezzapesa, M.; Francone, M.; Giannetta, E.; Papa, S.; Gambardella, C.; Sciomer, S.; et al. Right ventricular remodeling in idiopathic pulmonary arterial hypertension: Adaptive versus maladaptive morphology. J. Heart Lung Transpl. 2015, 34, 395-403. [CrossRef]

17. Naeije, R.; Vanderpool, R.; Peacock, A.; Badagliacca, R. The Right Heart-Pulmonary Circulation Unit: Physiopathology. Heart Fail. Clin. 2018, 14, 237-245. [CrossRef] [PubMed]

18. Badagliacca, R.; Rischard, F.; Papa, S.; Kubba, S.; Vanderpool, R.; Yuan, J.X.; Garcia, J.G.; Airhart, S.; Poscia, R.; Pezzuto, B.; et al. Clinical implications of idiopathic pulmonary arterial hypertension phenotypes defined by cluster analysis. J. Heart Lung Transpl. 2020, 39, 310-320. [CrossRef]

19. Badagliacca, R.; Poscia, R.; Pezzuto, B.; Papa, S.; Reali, M.; Pesce, F.; Manzi, G.; Gianfrilli, D.; Ciciarello, F.; Sciomer, S.; et al. Prognostic relevance of right heart reverse remodeling in idiopathic pulmonary arterial hypertension. J. Heart Lung Transpl. 2017. [CrossRef]

20. Sciomer, S.; Badagliacca, R.; Fedele, F. Pulmonary hypertension: Echocardiographic assessment. Ital. Heart J. $2005,6,840-845$. 
21. Miotti, C.; Papa, S.; Manzi, G.; Scoccia, G.; Luongo, F.; Toto, F.; Malerba, C.; Cedrone, N.; Sciomer, S.; Ciciarello, F.; et al. The Growing Role of Echocardiography in Pulmonary Arterial Hypertension Risk Stratification: The Missing Piece. J. Clin. Med. 2021, 10, 619. [CrossRef] [PubMed]

22. Raina, A.; Benza, R.L. Ambulatory Hemodynamic Monitoring in the Management of Pulmonary Arterial Hypertension. Adv. Pulm. Hypertens 2014, 13, 81-85. [CrossRef]

23. Abraham, W.T.; Stevenson, L.W.; Bourge, R.C.; Lindenfeld, J.A.; Bauman, J.G.; Adamson, P.B.; CHAMPION Trial Study Group. Sustained efficacy of pulmonary artery pressure to guide adjustment of chronic heart failure therapy: Complete follow-up results from the CHAMPION randomised trial. Lancet 2016, 387, 453-461. [CrossRef]

24. Givertz, M.M.; Stevenson, L.W.; Costanzo, M.R.; Bourge, R.C.; Bauman, J.G.; Ginn, G.; Abraham, W.T.; CHAMPION Trial Investigators. Pulmonary Artery Pressure-Guided Management of Patients With Heart Failure and Reduced Ejection Fraction. J. Am. Coll. Cardiol. 2017, 70, 1875-1886. [CrossRef] [PubMed]

25. Ponikowski, P.; Voors, A.A.; Anker, S.D.; Bueno, H.; Cleland, J.G.F.; Coats, A.J.S.; Falk, V.; González-Juanatey, J.R.; Harjola, V.P.; Jankowska, E.A.; et al. 2016 ESC Guidelines for the diagnosis and treatment of acute and chronic heart failure: The Task Force for the diagnosis and treatment of acute and chronic heart failure of the European Society of Cardiology (ESC)Developed with the special contribution of the Heart Failure Association (HFA) of the ESC. Eur. Heart J. 2016, 37, 2129-2200. [CrossRef] [PubMed]

26. Benza, R.L.; Doyle, M.; Lasorda, D.; Parikh, K.S.; Correa-Jaque, P.; Badie, N.; Ginn, G.; Airhart, S.; Franco, V.; Kanwar, M.K.; et al. Monitoring Pulmonary Arterial Hypertension Using an Implantable Hemodynamic Sensor. Chest 2019, 156, 1176-1186. [CrossRef]

27. De Lazzari, C.; Genuini, I.; Pisanelli, D.M.; D'Ambrosi, A.; Fedele, F. Interactive simulator for e-Learning environments: A teaching software for health care professionals. Biomed. Eng. Online 2014, 13, 172. [CrossRef]

28. Larrabide, I.; Blanco, P.J.; Urquiza, S.A.; Dari, E.A.; Vénere, M.J.; e Silva, N.D.; Feijóo, R.A. HeMoLab—Hemodynamics Modelling Laboratory: An application for modelling the human cardiovascular system. Comput. Biol. Med. 2012, 42, 993-1004. [CrossRef]

29. Fresiello, L.; Ferrari, G.; Di Molfetta, A.; Zieliński, K.; Tzallas, A.; Jacobs, S.; Darowski, M.; Kozarski, M.; Meyns, B.; Katertsidis, N.S.; et al. A cardiovascular simulator tailored for training and clinical uses. J. Biomed. Inform. 2015, 57, 100-112. [CrossRef]

30. Arts, T.; Delhaas, T.; Bovendeerd, P.; Verbeek, X.; Prinzen, F.W. Adaptation to mechanical load determines shape and properties of heart and circulation: The circadapt model. Am. J. Physiol. Heart Circ. Physiol. 2005, 288, H1943-H1954. [CrossRef]

31. De Lazzari, C.; Quatember, B.; Recheis, W.; Mayr, M.; Demertzis, S.; Allasia, G.; De Rossi, A.; Cavoretto, R.; Venturino, E.; Genuini, I. Lung assist devices influence cardio-energetic parameters: Numerical simulation study. Annu. Int. Conf. IEEE Eng. Med. Biol. Soc. 2015, 2015, 4515-4519. [CrossRef] [PubMed]

32. Capoccia, M.; Marconi, S.; Singh, S.A.; Pisanelli, D.M.; De Lazzari, C. Simulation as a preoperative planning approach in advanced heart failure patients. A retrospective clinical analysis. Biomed. Eng. Online 2018, 17, 52. [CrossRef] [PubMed]

33. Gaudenzi, F.; Avolio, A.P. Lumped parameter model of cardiovascular-respiratory interaction. Annu. Int. Conf. IEEE Eng. Med. Biol. Soc. 2013, 2013, 473-476. [CrossRef] [PubMed]

34. Marconi, S.; De Lazzari, C. In silico study of airway/lung mechanics in normal human breathing. Math. Comput. Simul. 2020, 177, 603-624. [CrossRef] 